\title{
Compiling the White Inventory: the practice of whiteness in a British primary school
}

\author{
SARAH PEARCE \\ Manchester Metropolitan University, UK
}

\begin{abstract}
Whiteness studies' has become a significant theme in writing about ethnicity and education over the past decade. Unlike both multiculturalism and anti-racism, whiteness theorists suggest that whiteness can be seen not as a biological fact, but as a social construction, and seek to examine white behaviour and assumptions as a first step toward resisting that behaviour. While its place in the academic world seems secure, its theories have had a limited impact on practitioners, particularly in Britain. Despite urgent calls by many writers in the field of whiteness studies, the number of white teachers attempting to understand how their own ethnicity affects their work appears negligible. In this paper I seek to begin to address that problem by applying a model of white attitudes to my own thinking and behaviour as a white teacher in a multi-ethnic primary school. It is suggested that this act of recording and reporting on the taken-for-granted behaviour of whites must be the first step toward decentring whiteness, and thus of providing a more equitable education for all children.
\end{abstract}

\section{INTRODUCTION}

For those working in education over the past 30 years, approaches to 'race' have been dominated by two competing philosophies. The approach of multiculturalism, familiar in many schools, is that racial harmony can be achieved through a deeper experience and understanding of other cultures. Anti-racists, on the other hand, deride gestures such as samosa-making as meaningless in the face of institutionalised racism. Yet over the past decade both schools of thought have been criticised. The superficiality of much of the work which has passed for multicultural education is rightly condemned, but the refusal of anti-racists to recognise the importance of culture as a marker is also now seen as misguided by many (Donald \& Rattansi, 1992; May, 1999). Further, the dualism which underpins the approach of some strands of anti-racism, in which whites are depicted as always and inevitably the oppressors, and blacks as passive victims, has also been called into question. How, then, are teachers to think about 'race' and ethnicity?

In the first place, teachers need to examine their own ethnicity. Given that the vast majority of teachers in Britain are white, this is likely to be an unfamiliar 
notion. Most white people are not accustomed to thinking of themselves as members of an ethnic group. But paradoxically, in order to begin to get beyond the black/white dualism, I propose that white teachers need to examine their own 'whiteness'. We need to consider how far our preconceptions and assumptions derive from our membership of the dominant group in society, conceiving of whiteness not as a biological fact, but as a social construction. It is on this point that ideas about whiteness offer a more positive message to practitioners than anti-racism, while carrying forward that movement's commitment to challenge institutionalised racism. If we can learn to see how being white influences our behaviour and attitudes toward others, both white and non-white, then we can begin to 'unlearn' that behaviour, to disown the practice of whiteness.

In this paper I examine some of the key aspects of whiteness studies which have emerged over the past decade. I then put forward a model of the practice of whiteness, and examine my own attitudes and behaviour in the classroom against these characteristics, using data collected through practitioner research over a four-year period.

\section{KEY ASPECTS OF WHITENESS STUDIES}

Much of the writing on whiteness currently comes from the USA, where it first emerged as a significant field of study, and there remains much to be done in terms of putting 'whiteness studies' to work in a British context. Frankenberg (1993), who examined how ethnicity influenced the lives of 50 white women, suggests that whiteness can be seen as having three dimensions:

- it is a standpoint, a place from which to view the world;

- it is a position of structural advantage;

- it is a set of unmarked cultural practices.

\section{Whiteness as a Standpoint}

Ideas about 'race' in the West are inextricably bound up with the history of colonialism. Since the earliest imperialist expeditions Western Europeans and their descendants have become accustomed to being the viewer and the judge of all they encountered. Whiteness is something that defines the 'other' but is not itself subject to others' definitions (Bonnett, 2000). Whites are simply the norm: it is for others to label themselves as other than that norm. This is the great power of claiming no 'race': you can claim to be neutral, to speak for the whole of humanity. Troyna (1994) noted the tendency in the sociology of education to depict whiteness as the norm. The teachers in the studies he analyses are unraced, i.e. they are white. He suggests that this 'deracialised' approach has led to other studies which, 'in their determination to redress the balance, focus purely and simply on the experience of teachers from ethnic minority groups. These studies have the potential to reinforce ethnocentric conceptions of 
"normality" by addressing the marginality, exclusiveness, the "Otherness" of ethnic minority teachers' (p. 327).

\section{'Whiteness' as a Location of Structural Advantage, of Race Privilege}

Dyer (1997) notes that successful whites refuse to believe that their ethnicity has any part to play in their achievements, preferring to hold on to the belief that their success is due to individual effort and talent. This desire to look at western society as a meritocracy, even as the criteria are skewed to favour the dominant group, is a strong feature of whiteness. It involves a belief that we all have the same chances in life: a refusal to acknowledge structural inequality. This 'colour-blind' view is assumed by many to be the most enlightened, non-racist approach to take to 'race', and can be considered the dominant discourse, the 'polite language of race'. Frankenberg's term for the discourse, 'colour and power evasive', is a reference to a more recent variation on the 'colour-blind' theme, which appears to recognise and value cultural differences, while still refusing to acknowledge the role of race in structuring social inequalities. Jones quotes a characteristic view among white British trainee teachers: 'as far as I'm concerned ... a child is a child, it doesn't matter what sex they are or what colour they are, what religion' $(1999$, p. 44). These white students found it hard to differentiate between the racism of social structures and the accusation that they were personally racist. Within the colour and power evasive discourse, racism, where it exists, is solely a matter of personal prejudice, so that to raise the issue at all is to suggest that individuals hold racist beliefs. Several studies of racism awareness components in Initial Teacher Education (ITE) report hostile and uncomprehending responses from white students when they were challenged on these issues (Jones, 1999; Hunter \& Nettles, 1999; Gaine, 2001). Perhaps more disturbing yet is the extreme rarity of such courses.

\section{Whiteness is a Set of Unmarked Cultural Practices}

[T] he starting point of critical elaboration is the consciousness of what one really is, and is 'knowing thyself' as a product of the historical process to date, which has deposited on you an infinity of traces, without leaving an inventory. The first thing to do is to make such an inventory. (Gramsci, 1971, p. 324)

Many of those women in Frankenberg's study who viewed difference as a positive attribute did so as a result of a feeling that their own culture was somehow deficient, or even that they had no culture. This idea is also present in conceptions of whiteness in Britain: Baumann (1996) notes in the talk of the white Londoners he studied a view that there was no such thing as English culture. To them, culture was something their African-Caribbean and Muslim neighbours possessed. This inability to recognise one's own culture leaves intact the idea that whiteness is a neutral place from which to look at others. The only 
way in which whiteness can take its place alongside, rather than pre-eminent among, other cultural practices is if it can be identified and examined. The task, therefore, is to compile Gramsci's inventory, to delineate what white cultural practices actually are. McIntosh (1992) with her list of 46 examples of white privilege may have been the first white person to attempt to catalogue the practice of whiteness (naturally, non-white commentators have been able to compile such lists for centuries). She cites such taken-for-granted behaviours and attitudes as being able to criticise her government without being considered an outsider, and being confident that her children will be accepted at school.

The implications of whiteness studies for teachers are enormous. Teachers are inevitably the mediators of the dominant discourse, and middle-class white teachers are also successful products of the dominant culture. It is not difficult to read the many studies (e.g. Wright, 1992; Basit, 1997; Haw, 1998) that suggest that white teachers sometimes adversely affect the education of ethnic minority students as a result of the practice of whiteness. The issues are immensely complex, and Levine-Rasky (2000a) fears that elitist theoreticians of whiteness are moving too fast for white educators, and that it is asking too much to expect them to 'change with inadequate exploration of the implications for their perspective, their practice, or indeed their formative consciousness about whiteness' (2000a, p. 273). She advocates that theoretical work on whiteness be integrated with work on teacher education, and this is beginning, though the work on both sides of the Atlantic has focused on trainee teachers, and, again, work in Britain appears very limited (see Gaine, 2001). In the following section I seek to apply the force of this theoretical work to my own practice as a white primary school teacher.

\section{METHODS}

The research was undertaken over a four-year period in an inner-city primary school in a working-class area of Northern England where I had been a class teacher for some years. Over $80 \%$ of the school's pupils were of Pakistani or Bangladeshi origin, the remainder being mainly from white and AfricanCaribbean families. In contrast, at the beginning of the study only two staff members were from an ethnic minority, though this figure had increased by the end of the study, with the appointment of three new staff members, two of them classroom assistants. The school had a strongly supportive and achievement-oriented ethos, and relationships between staff and children were characterised by warmth and trust.

The approach to the research described in this article places the teacher researcher in a key role as both the observed and the observer of the situation described. Teacher narrative is at the core of the data, in the form of a journal in which I recorded incidents and conversations relating to the study that took place between teacher and children, and among the children themselves in classroom sessions, and during breaks. In it I also noted my personal reactions to those events I described. This process of articulating and reflecting on my 
actions and attitudes deepened my understanding of my role in the classroom, and influenced my subsequent behaviour. In addition, the lengthy period over which this writing extended enabled me to chart the changes in my conception of the issues I was dealing with in the classroom (England \& Brown, 2001). In order to provide a point of comparison for these reflections I also conducted semi-structured interviews with ten colleagues, each lasting between 30 minutes and two hours. During the interviews I made notes, and then submitted a written report of the conversation to each interviewee for verification. These interviews served to illuminate my own perceptions, whilst also initiating a dialogue with colleagues on issues of 'race' and ethnicity.

The data were initially analysed for recurring themes and patterns, paying particular attention to issues that appeared to challenge my own way of thinking. Textual analysis of units of the data served to uncover deeper assumptions and ways of seeing. While the research process described here is a very personal one, and in no way generalisable in the traditional sense, the value of disseminating it lies in its ability to contribute to the 'ever increasing catalogue of particular social processes and practices which researchers can draw upon to help sensitise them to and consequently identify the complex range of processes that could be occurring in their school' (Connolly, 1998, p. 135).

\section{THE PRACTICE OF WHITENESS}

In this section I examine the data from my practitioner enquiry under four organisational headings, borrowed from a conceptualisation of the views of the white teacher candidates suggested by Levine-Rasky (2000b). In doing so I wish to add to the catalogue of work being done on how the 'practice' of whiteness works on a day-to-day basis.

\section{(1) The problem is how people cope with difference, not that whites dominate}

My initial perception of the problem was that the curriculum I taught excluded the history and culture of the vast majority of the children in my class. Thus I was initially drawn to the multiculturalist project of adapting the curriculum to include material from other cultures. Early work on the project was concerned with finding out more about Islamic history and philosophy. This locates my thinking at the time among those who feel that racial conflict and discrimination are a result of the difficulties individuals have in coming to terms with ethnic and cultural differences. Later, I became interested in the development of identity among young Muslims, and recorded my interests in my journal thus:

I want to examine first the extent to which Muslim schoolchildren perceive a conflict between the liberal western culture of the school and the Islamic culture of the home, and then the part which I as a (white) teacher have to play in that process. 
Later still, I saw my project as an attempt to answer the question: 'how do Muslim children reconcile their experiences of schooling with the very different values and traditions they bring from home?'

Though the first quote shows that I acknowledge the need to explore my own role, this is very explicitly a secondary goal. The bracketed reference to my own ethnicity reveals a dawning realisation that this may be fundamental. In the second, formulated for a more formal purpose, I have removed an examination of my own part in the process, and in particular the role of my whiteness. I chose to move away from the influence of my own ethnicity and to focus instead on to the behaviour of the non-white group. In conversation, a few teachers appeared to articulate a similar attitude. One colleague was concerned that: 'African-Caribbean children had problems with identity, and that their problems with aggression were a direct outcome of this. She felt the difficulties came from their own search for a place, rather than other children's hostility.' This view locates the 'problem' very explicitly with the AfricanCaribbean children themselves. The idea that racism has any part to play is rejected-both explicitly, in relation to other children, and implicitly, in the exclusion of the role of teachers from the discussion. Thus the problem is conceptualised as residing with ethnic minority groups, rather than with white hegemony. But a comment from another colleague who also saw children struggling with problems with identity suggests a more complex picture: 'They've got people at the National Curriculum whose job it is to say "do this and this". They could organise this-if we could be given links ...'. I asked why she thought this didn't happen: 'because England is predominantly white and what do they care?'.

This teacher was explicit in identifying white hegemony as the root of the problem. Comments such as this serve to underline the fact that it is not always and only a lack of awareness that prevents teachers from providing a more equitable education.

\section{(2) Whiteness is never referred to-whiteness is invisible, normalised}

In the classroom, the normalisation of whiteness can take many forms: discouragement of the use of minority languages; the use of 'multicultural' literature only when required by the National Literacy Strategy; disapproval expressed of other cultural norms such as large families. In my journal I recorded a belated understanding of the importance of the choice of classroom materials. The children I refer to have Bengali, Pakistani or mixed white and African-Caribbean backgrounds.

The stimulus for the story was a photo I'd selected of a white boy lying on what was clearly a classroom floor. They named the boy Tom, and then created a story in which his arch rival was a boy named Robert. Though the photo required a white name, it reminded me of the 
discussion about the way the mostly Asian and African-Caribbean children in the school invariably choose white names for their characters. On the other hand, what was I doing providing a photo of a white boy, if I'm so concerned about this phenomenon?

A similar inability to challenge the invisibility of whiteness can be seen in the following exchange between myself and a group of nine-year-olds. I had brought in a series of photographs of people as a stimulus for some descriptive writing. I recorded the response:

The one which excited the most comment was a photo of a group of men in graduation garb. They were all black, and were smiling against a blurred background which looked like trees in the sunshine. L said, 'oh, it's the Zulus' and laughed as I put it up. They all placed the men as being from Jamaica at first, and then decided on Africa. I asked if the photo might have been taken here, and they said, 'no', and when I asked why, said, 'because they're black'. There then followed a discussion about why some people are black:

My uncle says people are black because they drink too much coffee and then go out in the sun.

People are black because they haven't got enough to eat.

L's reference to the Zulus reveals a popular racist conflation of a black skin with an aboriginal African identity, one which conjures up images of cannibalism, war paint and other strange exotic practices. The other children's refusal to consider the possibility that the men were British, or even that they were in Britain at the time 'because they're black' is mystifying in the context of the school in which there were a number of different races, including several families from African or African-Caribbean backgrounds, including L's mother.

There is much to consider here in terms of the children's attitudes to race. Here I wish to focus on the influence of whiteness on my way of seeing. By permitting this deconstruction of blackness as a strange exotic property while failing to see the obvious potential for a parallel discussion on why people are white I unwittingly reinforced the notion of blackness as a departure from whiteness, the norm that does not need to be examined or deconstructed. Crucially, it was not until much later that I even saw that I could have challenged the invisibility and power of whiteness by initiating such a conversation.

\section{(3) Racism is a personal failing, not a structural issue}

I noted above that whites tend to view racism as an individual character defect, and often do not understand the notion of the racism of social structures. Linked to this is a belief among many whites that one can only be guilty of a racist act if that act was intentionally racist. This conceptualisation of racism can 
be seen in my ambivalence as I compare two incidents in which a child had been referred to as having 'slanty eyes':

A similar thing happened in another class, recounted to me by the teacher. D, who is Vietnamese, was attacked by A, a Pakistani boy, who called him 'slanty eyes, and flat face', reducing him to tears. I remember an incident in which someone referred to his eyes as 'slanty' earlier in my diary. On that occasion he cried too, and I did nothing more than have a 'serious talk' with the group. On that occasion, it seemed clear that no offence had been intended (does it matter?). But here it seemed obvious that the intent was malicious.

The earlier incident caused much hurt, but I did not feel it warranted anything more than a 'serious talk' because it had seemed clear to me, from the offending child's reaction to D's tears, that she was not in her mind making a racist remark. But my parenthetic question, 'does it matter?', reveals my own questioning of the offending child's point of view as the appropriate place from which to start. D clearly saw the remark as racist, and that is the more significant point of view. Again, I reveal a tendency to excuse apparently racist incidents in conversation with a colleague about the nature of young children's racism:

Small children had sometimes used racist names but she didn't feel they were being deliberately racist. I asked whether she thought they used it as a way of retaliating when they were upset about something else, and she agreed this was probably true.

There is evidence for the fact that children who do not hold racist views sometimes use racist insults. Hatcher (1995) suggests that some children do so 'in the heat of the moment', and then regret it, while others regard such labels as legitimate weapons on the same level as pejorative references to a person's weight or height. What links these two incidents is my conception of 'deliberate racism' as the sole problem. Other conversations with colleagues revealed a similar pattern. Asked if they had witnessed any racism in school several replied that they had not seen anything they regarded as 'blatantly', 'really' or 'specifically' racist. The use of these qualifiers may reveal a distinction similar to my own between intentional and unintentional acts. That there is a distinction to be made is not at issue. My concern is that rejecting the significance of the casual use of racist insults and the unintentional hurt caused by stereotypical racial references is concomitant to rejecting the significance and power of structural racism. The MacPherson report into the murder of Stephen Lawrence was explicit in defining 'unwitting' racism. Exchange the words 'police',' and 'traditional' for 'teaching' and 'white' and the description may be said to apply equally to the education system:

Unwitting racism can arise because of lack of understanding, ignorance or mistaken beliefs. It can arise from well intentioned but patronising words or actions. It can arise from unfamiliarity with the behaviour or 
cultural traditions of people or families from minority ethnic communities. It can arise from racist stereotyping of black people as potential criminals or troublemakers. Often this arises out of uncritical selfunderstanding born out of an inflexible police ethos of the 'traditional' way of doing things. (MacPherson, 1999, p. 22)

Even when white teachers do perceive an incident as racist, some research suggests that they do not respond effectively. Troyna and Hatcher (1991) consider that the absence of an anti-racism policy in many schools is due to a belief among many teachers that racist incidents are neither sufficiently common nor serious to demand the introduction of such a policy. This leads to an ad hoc approach to individual incidents. This entry in my journal records my initial reluctance to tackle racist remarks from children:

I had a session with three children who are learning English. We were looking at a book in the Oxford Reading Tree series, which concerns a white family this group is familiar with. The book we were looking at introduces Wilf and Wilma, two African-Caribbean characters, for the first time. F, who came from Bangladesh about a year and a half ago, looked at the picture in the book, pointed to Wilf and Wilma:

F: I don't like them.

SP: why not?

F: I like him, and him and her and her (pointing to the white characters), but I don't like them.

SP: why not, F?

F: their hair ... it's (he touched his hair with his fingers, in a spiral motion) I don't like it.

I did not know what to say. Should I have challenged him? How?

It is difficult now to explain or understand why I did not respond to this remark in any way. My final comments suggest that I knew that I should have said something, but even after a period of reflection I did not know what an appropriate response would have been. By allowing $\mathrm{F}$ to make such a remark without challenging it I colluded with him. Two terms later, when I witnessed $\mathrm{F}$ become the victim of racism, I had learned that I needed to respond to such incidents, but was still agonising over how best to do so:

Looking at a picture of a pelican with a fish in its mouth:

$S$ : Bengalis eat fish.

F (clearly irritated): So? Everyone eats fish.

SP: I eat fish.

S: I don't. Not like them.

F's reference to the common 'Bengali fish' slur. I supported F, but not with any authority. I have acted like this before. How did F feel? Did he feel that his nationality was being degraded and that, because the teacher did little, that this was officially acceptable? Or did he feel, as 
I intended, that S's remarks had been quietly rubbished, and that he had emerged on top?

Other studies have shown that this tendency to play down racist incidents is not unusual (Gillborn \& Gipps, 1996; Bigger, 2000). When I related the above conversation to a colleague, she articulated the dilemma experienced by many white teachers: 'The difficulty is do you make something of a racist incidentdoes that make it worse? Or if not are you brushing it under the carpet?'.

Bonnett (2000) suggests that whites find it easy to ignore the issue of racism and have remained unengaged by the anti-racist project. Again I am able to see this attitude reflected in my own behaviour. I recorded in my journal my reaction to a discussion I had with two groups of children, nine- and ten-yearolds, about their experiences of racism:

Most striking - the number of stories the children had about racist incidents $-\mathrm{P}$ had many stories of violent confrontations. He dreamed of living in the US where it's a 'loving country'. Their shared view of Britain as a place where you have to be careful-some people won't accept you. Also moved and shaken by the lack of inhibition with which they spoke about it. The sense that this is very much a live issue for them-it's all around them. They had so much to say.

The two features of this entry are my shock at both the extent of the children's experience of racism, and their candour in articulating their feelings about it. Despite working for several years in a multicultural community, as a white woman I have very rarely been aware of racism. Perhaps even more striking for me was their lack of inhibition in discussing and trying to understand it, which is so much at odds with my own attitude, so often characterised by fear.

\section{(4) 'We don't know what to say'}

A few colleagues admitted to sharing these fears, variously describing situations of uncertainty as 'a minefield', getting into 'deep water', and worries over 'saying the wrong thing'. The fear here was often of unconsciously saying something that others would construe as racist:

$\mathrm{R}$ talked about the issue of talking about Pakistan as the children's home country-'am I being racist when I say that? I feel as though I am saying the wrong thing when some of the children have never been to Pakistan, for example'.

Another colleague noted during this conversation that 'even though the three of us were colleagues and had socialised together, we were still pussyfooting around because we don't want to be seen as racist'. Some commentators suggest that the fear whites feel when forced to confront racism, and the dominance of their group in general, is the fear of ultimately losing their status, and their material and psychological advantages (see, for example, Sleeter, 1996). In 
contrast Frankenberg (1993) suggests that well-intentioned white people often feel deeply insecure about whether they have the credibility to talk about racism This issue looms large in my later attempts to address the under-representation of non-white groups in the curriculum. This entry in my journal records my feelings when I learned I was to be joined in the classroom by T, a supply teacher. The lesson concerned immigration and emigration in Britain in the 1950s and 60s:

I have no opportunity to discuss the lesson with her before the day, and I feel very self-conscious about talking about issues of migration and the ill-treatment received by immigrants in front of a Pakistani-born woman who is given no role in the proceedings. What is this, liberal white guilt, or is it OK to think that there is something odd about a white woman talking about migration while a Pakistani woman stands by?

After the lesson I recorded:

I discussed my plan for the lesson very briefly with $T$ at lunchtime, and she agreed to take a group, but did not comment on the material. I didn't say anything of how I felt either. We spoke about how difficult the class is, and how hard it is to get them to listen to each other. During the lesson the children were quite interested in the texts, and I tried to highlight the main issues, which were that people were invited to come to Britain, and the racism they encountered. The children ... did not seem inclined to discuss it, and I did not press very hard for them to do so. Why? Because $\mathrm{T}$ was there. Why did that make such a difference? Because I was afraid of saying the wrong thing. After the children had gone we had a chat about the children, and agreed it was a shame there had not been more of a discussion. We were both content to blame the children for that ... it was very friendly, and yet I had not been able to say what was on my mind. Had she?

My analysis of these extracts identifies two apparently common features of the practice of whiteness. In the first place I note the complete lack of communication between us. I complained that I would have no opportunity to discuss the lesson with her, but took no steps to try to contact her. I discussed the plan 'very briefly' but did not mention how I felt about it. At the end of the lesson we spoke about how it had gone in terms of classroom management, but again said nothing about the real issues. It seems I could not bring myself to admit my fear that I was not sufficiently experienced in approaching sensitive issues with children, and in particular that, as a white woman, I would not be able to deal appropriately with the material. Was I unwilling to surrender my superior position, or was I simply reluctant to make myself vulnerable to someone I did not know?

The second feature of whiteness this incident exemplifies is my desire to allocate roles in the lesson on the basis of 'race'. Being white, I felt I did not 
have as much right to talk about issues of racism as T, my Asian colleague, who, by virtue of her 'race', was the expert. Such feelings may be traced back to the legacy of 'moral anti-racism' (MacDonald et al., 1989) which over-simplified racism as only ever white on black oppression. This simplistic model essentialises the experience of both whites and blacks, offering whites no escape from the role of racist, and forcing blacks into the role of passive victim. Such a dualistic conception of the problem also traps blacks in the unasked-for role of experts on racism and spokespeople for all ethnic minorities. Nayak records the disappointment of a black teacher who felt she had been appointed partly because of her ethnicity: 'I objected to her seeing me as having a specific role because I was different to any other teachers. I was the only Black teacher on the staff, therefore I had this particular role' (1997, p. 64).

Gillborn (1996) also suggests that such a model does not reflect the lived reality of many working-class whites, who would find the idea of being part of a powerful elite 'absurd' (p. 173). This argument highlights the need for any study that seeks to understand how 'race' works in society to include a consideration of how class, and indeed gender, intersect with 'race', and the way in which each of these differences assumes more or less importance according to the context. Basit (1997) suggests that the low expectations and prejudice shown by both middle-class white and Muslim teachers in her study was a result not of racial, but of class prejudice. Some teachers in my study were aware of these issues. One middle-class teacher initiated a conversation about class prejudice during interview, and spoke of Basil Bernstein as a continuing influence in her work. Another, who perceived herself as sharing a working-class background with her students, was able to invoke this shared experience to cut across an ethnic divide:

She remembers her own education, and her lack of ambition, and urges the children to get out of that situation. She says to them things like, 'I could give up this job and go and work in Australia if I wanted to, because I've got an education - so could you'. She said that you might have a cultural connection with the children, or it might be an economic one: 'I've got the economic one. It drives me mental when they say "I want to work in a supermarket". They know it's not a good job-they don't think they're clever enough to be doctors. I say, 'is that what your mum wants?' and they say, 'no, she wants me to be a doctor', and I say, 'yes, well!'

This teacher was explicit in likening the difficulty white teachers may have in multi-ethnic schools with problems between middle-class teachers and workingclass students. The issues become even more complex with the addition of gender to the equation. Several studies have noted the way in which gender positions children differently in relation to each other and to their teachers (Mac an Ghaill, 1988; Connolly, 1998; Bhatti, 1999). It appears that discourses on these two positionings can either work with or against each other. For example, African-Caribbean boys may be perceived as troublesome by mainly white 
teachers because they carry the burden of a double stereotype: that of AfricanCaribbean children as physical and assertive, plus the stereotype of boys as naturally aggressive. On the other hand the stereotype of girls as obedient and quiet may counteract the stereotype of African-Caribbean children so that black girls are less often the subject of negative attention from teachers.

\section{DISCUSSION}

One way out of the debilitating conception of whiteness I have described in this article is to conceive of it as an abstract and socially constructed process, rather than an inescapable biological fact (Levine-Rasky, 2000a). In this way, individuals are not asked to bear the burden of personal guilt: they are able to see whiteness as a political and historical artefact, and one that can eventually be rejected. This model offers whites the possibility of moving beyond guilt and fear towards positive action for greater social justice. The first step is to identify what, among whites, has for so long remained unidentified: whiteness as a cultural identity that defines the way we behave, speak and look at the world. When we know what it is we are talking about we can begin to change that way of seeing, to decentre whiteness, to take its place alongside, not pre-eminent among, other cultural and ethnic norms.

This early attempt to define and analyse the practice of whiteness in the classroom close up is part of that project. Clearly it has huge implications for all branches of education. What are the prospects for change? It is beyond the scope of this article to do more than sketch out a few possibilities. An obvious starting point is ITE, but the current emphasis on the bureaucratic and technical aspects of teaching at the expense of wider social and philosophical issues on training courses has left little room for a consideration of the effects of ethnicity and race in education (Bigger, 2000). Where such issues have been dealt with, the results have sometimes been counterproductive, because the approach taken has been too personal and accusatory (Gaine, 2001). Recasting the discussion in terms of whiteness as a way of behaving, as outlined above, may be a less confrontational way forward. However, the current conception of teacher education as on-the-job training is likely to afford fewer opportunities to address such complex theoretical issues, when practising teachers are sometimes no more aware of the issues than their students (Jones, 1998). In terms of the curriculum the Government's priorities are clear: numeracy and literacy dominate, and teachers teach with an eye to SATs and league tables. In this environment, in which measurable outcomes are required, there is little incentive in many schools to focus on issues such as racism, though committed individuals continue to do so. While I regard the introduction of citizenship as a positive development, offering some opportunities to discuss controversial issues, it is difficult to see how, in the already overcrowded curriculum, and without considerable staff development, such a project will have much impact. Further, we will be repeating the mistakes of the past if we attempt to parcel 'race' off into one corner of the curriculum, and feel we can ignore it elsewhere. 
What is required is a teaching profession which is aware of the issues and not afraid to confront them wherever they arise: be it in the curriculum, the corridor or the staff room. INSET provision explaining institutional racism in theory, and tracing it down to the workings of the school in practice, would be a first step towards that goal. Large and small-scale research projects by and with practitioners in education and related fields to examine how we are implicated in the process would offer opportunities to extend this work and provide a starting point for institutional change (e.g. Gillborn, 1996; Moore, 1999; Bigger, 2000; England \& Brown, 2001).There is also potential for examining the practice of whiteness at an institutional level, and the extent to which individual agency can influence or be influenced by the practices of the institution.

\section{CONCLUSION}

In making these suggestions I am acutely conscious that very much the same calls have been made at regular intervals over the past two decades (Troyna, 1987; Verma et al., 1994). While there is much useful work that could be done in terms of ITE, the curriculum and INSET, there is no escaping the responsibility of the individual practitioner to recognise the myriad ways in which the practice of whiteness has skewed perceptions of self and others. There is much that stands in the way of such a personal project: lack of intellectual, moral and financial support; fear of controversy; and an already almost intolerable workload. I have been fortunate to find the necessary support structure to begin such a project, the progress of which I have attempted to chart in this article. In it I have attempted to document some of the ways in which I have behaved and thought because of my whiteness: a tendency to see conflicts between white and non-white groups as a 'natural' result of the difficulties of living in a multicultural society, rather than sometimes the result of non-white groups resisting the dominance of whites. A habit of seeing whiteness as a neutral, core entity, and ethnicity as belonging to other, more marginal groups. Ignorance about the nature and extent of racism in society, and a willingness to excuse racist acts and comments for fear of causing a scene and 'saying the wrong thing'. A reluctance to discuss issues of race with people of other ethnic backgrounds because of guilt and fear. None of these facets of my whiteness are true for all whites, and none of them are fixed and immutable. They are ways of behaving that I have learned, and I have now begun the process of 'unlearning'. In these times of increased anti-immigration activity and heightened racial tension there is a need for those who see education as a vehicle for social justice to resist the new paranoia and assertiveness among some whites, and to communicate a more just way of thinking about 'race' to the next generation. But we cannot hope to do that until we have taken a long hard look at our own prejudices and preconceptions. 
Correspondence: Sarah Pearce, Manchester Metropolitan University, Institute of Education, 799 Wilmslow Road, Didsbury, Manchester M20 2RR, UK.

\section{REFERENCES}

Basit, T. (1997) Eastern Values, Western Milieu: identities and aspirations of adolescent British Muslim girls (Aldershot, Ashgate).

Baumann, G. (1996) Contesting Culture: discourses of identity in multi-ethnic London (Cambridge, Cambridge University Press).

Bhatti, G. (1999) Asian Children at Home and at School (London, Routledge).

Bigger, J. (2000) Race awareness and school ethos: reflections on school management issues, in: M. LeICESTER, C. MODgIL \& S. ModgIL (Eds) Institutional Issues-Pupils, Schools and Teacher Education (London, Falmer).

BonnetT, A. (2000) White Identities (Harlow, Pearson).

Connolly, P. (1998) Racism, Gender Identities and Young Children-Social Relations in the Multi-ethnic Inner-city Primary School (London, Routledge).

Donald, J. \& Rattansi, A. (Eds) (1992) 'Race', Culture and Difference (London, Sage/Open University Press).

DYER, R. (1997) White (London, Routledge).

England, J. \& BRown, T. (2001) Inclusion, exclusion and marginalisation, Educational Action Research, 9(3), pp. 355-370.

FrankenberG, R. (1993) White Women, Race Matters (Minneapolis, MN, Routledge).

GaINE, C. (2001) 'If it's not hurting it's not working': teaching teachers about race, Research Papers in Education, 16(1), pp. 93-113.

Gillborn, D. (1996) Student roles and perspectives in anti-racist education: a crisis of white ethnicity?, British Educational Research fournal, 22(2), pp. 165-179.

Gillborn, D. \& Gipps, C. (1996) Recent Research on the Achievements of Ethnic Minority Pupils (London, HMSO).

GramsCI, A. (1971) Extracts from the Prison Notebooks (London, Lawrence \& Wishart).

HAtcher, R. (1995) Racism and children's cultures, in: M. Griffiths \& B. Troyna (Eds) Anti-racism, Culture and Social Fustice in Education (Stoke on Trent, Trentham).

Haw, K. (1998) Educating Muslim Girls: shifting discourses (Buckingham, Open University Press).

Hunter, M. L \& Nettles, K. D. (1999) What about the white women? Racial politics in a women's studies classroom, Teaching Sociology, 27, pp. 385-397.

Jones, R. (1998) Multicultural education is dead. Paper presented at the BERA Annual Conference, Belfast, 27-30 August.

Jones, R. (1999) Teaching Racism or Tackling It? (Stoke on Trent, Trentham Books).

LEVINE-RASKY, C. (2000a) Framing whiteness: working through the tensions in introducing whiteness to educators, Race, Ethnicity and Education, 3(3), pp. 271-292.

LeVINE-RASKY, C. (2000b) The practice of whiteness among teacher candidates, International Studies in Sociology of Education, 10(3), pp. 263-284.

Mac an Ghaill, M. (1988) Young, Gifted and Black (Milton Keynes, Open University Press).

Macdonald, I., Bhavnani, R., Khan, L. \& John, G. (1989) Murder in the Playground. The report of the Macdonald Inquiry into Racism and Racial Violence in Manchester Schools (London, Longsight Press).

MAcPherson, W. (1999) The Stephen Lawrence Inquiry (London, HMSO).

McINTosh, P. (1992) White privilege and male privilege: a personal account of coming to see correspondences through work in women's studies, in: M. ANDERSEN \& P. HiLl Collins (Eds) Race, Class and Gender, an Anthology (Belmont, Wadsworth).

May, S. (1999) Critical Multiculturalism (London, Falmer).

Moore, A. (1999) Teaching Multicultured Students: culturalism and anti-culturalism in school classrooms (London, Falmer). 
Nayak, A. (1997) Tales from the dark side: negotiating whiteness in school arenas, International Studies in Sociology of Education, 7(1), pp. 57-79.

SleEter, C. (1996) White silence, white solidarity, in: N. IgNatiev \& J. Garvey (Eds) Race Traitor (New York, Routledge).

Troyna, B. (Ed.) (1987) Racial Inequality in Education (London, Tavistock).

Troyna, B. (1994) The everyday world of teachers? Deracialised discourses in the sociology of teachers and the teaching profession, British fournal of Sociology of Education, 15(3), pp. 325339.

Troyna, B. \& HATCher, R. (1991) Racist incidents in schools: a framework for analysis, fournal of Educational Policy, 6(1), pp. 20-31.

Verma, G., Zec, P. \& SkINNER, G. (1994) The Ethnic Crucible: harmony and hostility in multi-ethnic schools (London, Falmer).

WRIGHT, C. (1992) Multiracial primary school classrooms, in: D. GILL, B. MAYOR \& M. BLAIR (Eds.) Racism and Education-Structures and Strategies (London, Sage). 